\title{
Assessment of adiposity by bio impedance analysis: develop- ing a population specific equation for Sri Lankan adolescents
}

\author{
Maduka de Lanerolle-Dias ${ }^{1}$, Pulani Lanerolle ${ }^{1}$, Angela de Silva ${ }^{2}$, Sunethra Atukorala ${ }^{1}$ \\ Sri Lanka Journal of Diabetes, Endocrinology and Metabolism 2012; 2: 3-10 \\ (Index words: adiposity, fat mass, adolescents)
}

\begin{abstract}
Objective: Adiposity in adolescence is associated with chronic disease in adulthood, and assessment of body fat mass is vital for screening at risk populations. Adiposity is measured in many ways including bio impedence analysis. The objective of this study was to validate existing bio impedance analysis (BIA) equations on 15-19 year old adolescent girls and to derive a population specific equation for the prediction of percentage fat mass (\%FM) for adolescent girls.

Methods: Body composition of 15 - 19 year old, adolescent girls was assessed by the deuterium dilution method and BIA. Validity of existing equations for the prediction of \%FM of Sri Lankan adolescent girls were assessed prior to the derivation and validation of a new \%FM equation. The new equation was derived using linear regression analysis against the reference method, deuterium dilution.

Results: Existing BIA equations significantly $(\mathrm{p}<0.001)$ overestimated \%FM. The new equation derived for the prediction of \%FM of Sri Lankan adolescent girls significantly correlated with the reference method. There was no significant difference in \%FM obtained by the reference method (\%FM: $24.67 \pm 9.2)$ and the derived equation (\%FM: $24.9 \pm 6.3)$.

Conclusions: The new equation; $\% \mathrm{FM}=-74.065+0.671$ (height ${ }^{2} /$ resistance $)+0.049$ (resistance) + $2.080(\mathrm{BMI})$, is appropriate for the prediction of \%FM in Sri Lankan post pubertal adolescent girls, and may be validated for use on other South Asian populations.
\end{abstract}

\section{Introduction}

Adiposity in childhood and adolescence is one of the main determinants of insulin resistance, representing the metabolic basis for development of future chronic disease (1). Identification of at risk individuals during their adolescent years is essential in prevention, but many difficulties are encountered in assessing adiposity in adolescents due to variability in muscle mass, maturation and growth rates. Body mass index (BMI) is often used to assess adiposity, but does not differentiate between fat and non-fat components of body mass, resulting in inaccuracies in classification of individuals as overweight or obese (2). Other techniques of body fat assessment, such as densitometry and stable isotope methods are accurate, but expensive and impractical for routine screening. Bio impedance analysis (BIA) is based on applying a low level current through the body and measuring the impedance of tissues. These values are applied to an equation which is already programmed into the machine for the calculation of fat mass (3). The low cost and simplicity of assessment has popularized this method.
However, most BIA prediction equations programmed into bio impedance analysers are derived for Western populations and have poor validity in other populations $(4,5)$, with \%FM being overestimated in lean subjects and underestimated in obese individuals $(5,6)$. There are no published BIA equations for South Asian adolescents, with the few available equations being derived for the prediction of total body water (TBW), and through it, fat mass (7-9). Ideally, the available \%FM prediction equations should be validated in the population being assessed prior to use, or population specific prediction equations should be derived against a reference method to improve accuracy of BIA analysis (10).

While values of TBW, fat free mass (FFM), fat mass (FM) and their percentages can be obtained directly from the BIA instrument; FM can also be calculated using the impedance, resistance and / or reactance values, which may also be obtained from the instrument. Most BIA equations for the prediction of percentage fat mass (\%FM) have been derived on Caucasian and African American populations, employing height ${ }^{2} /$ resistance and body weight as the most significant predictors of \%FM. There

${ }^{1}$ Department of Biochemistry and Molecular Biology,

${ }^{2}$ Department of Physiology, Faculty of Medicine, University of Colombo, Sri Lanka. 
are no published population specific BIA equations for post pubertal adolescent girls in Sri Lanka or in other areas of similar ethnicity.

This study aims to validate existing BIA equations on a population of 15-19 year old adolescent girls against a reference method using stable isotopes (deuterium dilution method) and to derive a population specific equation for the prediction of \%FM for post pubertal adolescent girls.

\section{Methods}

\section{Study participants}

Healthy, post pubertal adolescent girls $(n=160)$ aged 15-19 years, were recruited for a study on body composition assessment. The sample was selected using a convenience sample representing both school going and non-school going adolescent girls living in public health midwife areas in urban and rural sectors of Colombo and Kalutara Districts in Sri Lanka. Ethical approval for this study was obtained from the Ethics Review Committee of the Faculty of Medicine, University of Colombo and written informed consent was obtained from all study participants.

\section{Assessment}

All body composition measurements were performed between 0830 and 1300 hours. The participants fasted for two hours from food and drink, did not perform strenuous exercise and emptied their bladders preceding the fat mass assessment by the reference method. The reference method for body composition assessments are densitometry or stable isotope analysis of TBW using deuterium oxide $\left(\mathrm{D}_{2} \mathrm{O}\right)$ which can be measured using an Isotope Ratio Mass Spectrometry (IRMS) or Fourier Transformed Infrared Spectrometry (FTIR) (11). The deuterium dilution technique was used as the criterion method for the estimation of total body water. The reference method used in this study was the two compartment model of assessment of TBW using the stable isotopes of $\mathrm{D}_{2} \mathrm{O}$ (deuterium dilution method) and measurement using FTIR, a spectroscopic technique that uses the absorption of infrared light to determine the concentration $\mathrm{D}_{2} \mathrm{O}$ of a sample (12). A single dose of $\mathrm{D}_{2} \mathrm{O}$ (Cambridge Isotope Laboratories Inc., MA, USA) was ingested by all subjects following the collection of a baseline saliva sample. Two other samples of saliva at 3 and 4 hours were obtained for analysis by FTIR after $\mathrm{D}_{2} \mathrm{O}$ administration. Enrichment was measured with a FTIR (8400S; Shimadzu, Vienna, Austria), with each sample being measured in duplicate. Quality control was in accordance with International Atomic Energy Authority guidelines (11).

FTIR analysis was carried out in the Department of Biochemistry and Molecular Biology, Faculty of Medicine,
University of Colombo. Prior to saliva measurement, the $\mathrm{D}_{2} \mathrm{O}$ standard was prepared by dilution of $\mathrm{D}_{2} \mathrm{O}$ with deionized water and the enrichment of the standard was confirmed by IRMS and further details of this assessment and analysis have been published previously (13).

\section{Bioelectrical impedance analysis (BIA)}

Bioelectrical impedance analysis (BIA) was measured using an SFB7 ImpediMed instrument (ImpediMed Limited, Australia). A multiple frequency current was used with four surface electrodes. The girls were asked to lie supine on a non-conductive surface with hands kept in a prone and slightly abducted position away from the trunk. In order to minimize interference, legs were abducted to a minimum of $20 \mathrm{~cm}$ between the two medial malleoli and thighs were parted to prevent touching each other. Surface electrodes for the source current were placed on the dorsal side of the third metacarpo-phalangeal joint of the left hand and third metatarso-phalangeal joint of the left foot. The sensing electrodes were kept at midway between the styloid process of ulna and radius on the posterior surface of the left wrist and midway between medial and lateral malleoli on the anterior surface of the left ankle. A minimum distance of $5 \mathrm{~cm}$ was maintained between the source and sensing electrodes to avoid any interference. If the natural distance between the source and sensing electrodes was less than $5 \mathrm{~cm}$, the sensing electrode was moved proximally till the desired distance was achieved (9). Conduction gel coated disposable surface electrodes were used and connected to the BIA machine via crocodile clips. The instrument was routinely checked on each day of sample collection using a test cell. Percentage fat mass values were obtained directly by the BIA instrument; in addition impedance, resistance and reactance values were obtained from the instrument and transformed into a measure of \%FM using BIA equations for the prediction of \%FM.

\section{Statistical analysis}

Statistical analysis was carried out using SPSS version 15 for Windows. Percentage fat mass values were obtained directly by the BIA instrument. Total body water values obtained by the reference method, were divided by the hydration factor ( 0.73 for adolescent girls), in order to derive the FFM. FM was calculated by subtracting FFM from body weight. Percentage fat mass was calculated as a fraction of body weight. Percentage fat mass by the reference method and BIA were compared using paired samples t-test for over / underestimation.

Assessment of validity of selected BIA equations to predict \%FM of the study population by comparison with \%FM from the reference method was as follows:

Selected BIA equations derived on adolescents and children, for the prediction of \%FM are given in Table 1. While the Kushner (14), Bray (15) and Houtkooper (16) 
Table 1. Existing BIA equations for the prediction of \%FM

\begin{tabular}{|c|c|c|}
\hline Equation & Author & $\begin{array}{l}\text { Population for which } \\
\text { equation was derived }\end{array}$ \\
\hline $\begin{array}{l}\% \mathrm{FM}=(\text { weight }-(0.59 \times(\text { height } \times \text { height } / \\
\mathrm{R})+0.065 \times \text { weight }+0.04) /(0.754 \times \text { weight })\end{array}$ & Kushner et al (1992) & $\begin{array}{l}0.02 \text { - } 66 \text { years, } \\
\text { Caucasian and Peruvian }\end{array}$ \\
\hline $\begin{array}{l}\% F M=(1-(0.4 \times(\text { height } \times \text { height } / \mathrm{R})+0.148 \times \\
\text { weight }+3.32) /(0.76 \times \text { weight })) \times 100\end{array}$ & Bray et al (2002) & $\begin{array}{l}10.79 \pm 0.05 \text { years, } \\
\text { Caucasian; African-American }\end{array}$ \\
\hline $\begin{array}{l}\% F M=-1.11 \times(\text { height } \times \text { height } / \mathrm{R})+1.04 \times \\
\text { weight }+15.16 \text { (height in } \mathrm{cm})\end{array}$ & Houtkooper et al. (1989) & 10 - 14 year old children \\
\hline $\begin{array}{l}\text { FFM }=0.56 \times(\text { height } \times \text { height } / Z)+0.22 \times \text { weight }+ \\
1.6 \times \text { sex }-0.22(\text { height in } \mathrm{cm}, \\
\operatorname{sex}(: \text { male }=1 \text {; female }=0))\end{array}$ & Wickramasinghe et al. (2008) & $\begin{array}{l}5 \text { - } 15 \text { year old } \\
\text { Sri Lankan children }\end{array}$ \\
\hline $\begin{array}{l}\text { FFM }=0.299 \times(\text { height } \times \text { height } / \mathrm{R})+(0.086 \times \text { height }) \\
+(0.245 \times \text { weight })+0.260 \times \text { age }+0.901 \times \text { sex }-0.415 \times \\
\text { ethnicity }(\text { height in } \mathrm{cm} \text {; Thai ethnicity }=1 \text {, others } \\
=0 \text {; } \operatorname{sex}(\text { male }=1 \text {, female }=0)\end{array}$ & Liu et al (2011) & 8 - 10 year old Asian children \\
\hline
\end{tabular}

R: resistance, Z: impedance

equations were directly applied to the population under study to obtain \%FM, the equations of Wickramasinghe (7) and Liu (17) were used to calculate FFM of the population and thereby FM (body weight - FM) and \%FM (fat mass $\times 100$ / body weight), based on the assumption that body weight $=$ FM + FFM. Pearson's rank correlation coefficients were obtained to assess the association between \%FM obtained from the reference method (deuterium dilution) and \%FM obtained from the selected equations. Mean \%FM values by the reference method was compared to values obtained by application of impedance and anthropometric values to existing equations using the paired samples t-test.

Derivation of a new BIA equation to predict \%FM was done as shown below:

The data of study participants were divided into cross validation and validation groups by sorting the age of girls in ascending order and including every third girl in the cross validation group. The preliminary prediction equation for \%FM was derived for the validation group, by linear regression analysis, using backward likelihood ratio, with \%FM (reference method) as the dependant variable, and resistance, height ${ }^{2} /$ resistance, body weight, BMI and age as independent variables. Predictability of the preliminary equation was evaluated using the crossvalidation group. The final prediction equation was derived after combining both validation and cross-validation groups, by linear regression analysis using the enter method. The independent variables for the final equation were determined by the preliminary equation. Level of agreement between the \%FM values calculated from the final derived prediction equation and the reference method was assessed using Spearman's correlation (r) and Bland Altman plots. Over/underestimation was assessed by Student t-test. High overall percentages of the predictions $(>70 \%)$ and significant $\chi^{2}$ values $(\mathrm{p}<0.001)$ were taken as indicative of goodness of fit of the models.

\section{Results}

Percentage fat mass by the reference method ranged from 9.2 to 49.1 with a mean $\% F M$ of $24.7 \pm 9.2$. Application of fat mass cut-off values by Sun et al (5) for women, classified $54 \%(n=86)$ of the girls as lean ( $\% F M \leq 25 \%)$, while $22 \%(n=35)$ had excess fat mass ( $\% F M \geq 33 \%)$. Percentage fat mass by BIA, when applied to the total population, significantly overestimated $(p<0.001)$ mean $\%$ FM obtained by the reference method (Figure 1). Direct assessment by the BIA overestimated \%FM in girls who were classified as lean by deuterium dilution ( $\% \mathrm{FM} \leq 25)$, and it underestimated \%FM in girls who had excess fat by deuterium dilution $(\% \mathrm{FM} \geq 33$ ) (Table2).

\section{Applicability of selected BIA equations to predict \%FM}

All selected BIA equations significantly overestimated body fat when compared to the reference method (Table 3). 
Table 2. Percentage FM by deuterium dilution method and BIA

\begin{tabular}{lcc}
\hline & Deuterium dilution & BIA \\
\hline $\begin{array}{l}\text { Total population }(\mathrm{n}=160) \\
\% \text { FM }\end{array}$ & $24.7(9.3)$ & $29.5(6.2)^{1}$ \\
$\begin{array}{l}\text { \% } \\
\text { \% (deuterium dilution }) \leq 25(\mathrm{n}=86)\end{array}$ & $17.3(3.9)$ & $29.2(4.8)^{1}$ \\
$\begin{array}{l}\text { \%FM (deuterium dilution }) \leq 33(\mathrm{n}=35) \\
\text { \% FM }\end{array}$ & $37.9(4.0)$ & $29.9(8.1)^{2}$ \\
\hline
\end{tabular}

${ }^{1}$ Significant overestimation by BIA, $\mathrm{p}<0.001$

${ }^{2}$ Significant underestimation by BIA, $\mathrm{p}<0.001$

Table 3. Percentage FM by the reference method (deuterium dilution), compared with \%FM calculated using selected BIA equations

\begin{tabular}{lcc}
\hline Method & Mean \pm SD & $\begin{array}{c}\text { Correlation with deuterium } \\
\text { dilution method }\end{array}$ \\
(Spearman's correlation coefficient)
\end{tabular}

${ }^{1}$ Significant overestimation from reference method, $\mathrm{p}<0.001$

${ }^{2}$ Significant correlation, $\mathrm{p}<0.001$

${ }^{3} \mathrm{FFM}$ equations, which were used to calculate FM and \%FM

Table 4. Comparison of anthropometric and impedance variables in validation and cross validation groups

\begin{tabular}{lcc}
\hline Variables & $\begin{array}{c}\text { Validation group } \\
(\text { mean } \pm \text { SD }) \\
n=107\end{array}$ & $\begin{array}{c}\text { Cross validation } \\
\text { (mean } \pm \text { SD) } \\
\text { group } n=53\end{array}$ \\
\hline Age (years) & $17.19 \pm 1.5$ & $17.25 \pm 1.4$ \\
BMI $\left(\mathrm{kg} / \mathrm{m}^{2}\right)$ & $19.9 \pm 3.5$ & $19.5 \pm 3.6$ \\
Body weight $(\mathrm{kg})$ & $47.2 \pm 8.3$ & $46.1 \pm 8.1$ \\
Height $(\mathrm{m})$ & $1.53 \pm 0.05$ & $1.53 \pm 0.07$ \\
Resistance $(\Omega)$ & $724.3 \pm 79.8$ & $737.4 \pm 89.3$ \\
height2/resistance $\left(\mathrm{cm}^{2} / \Omega\right)$ & $33.0 \pm 3.8$ & $32.5 \pm 4.4$ \\
\%FM (BIA) & $29.4 \pm 6.2$ & $29.7 \pm 6.3$ \\
\%FM (deuterium dilution) & $25.1 \pm 9.4$ & $23.8 \pm 9.0$ \\
\hline
\end{tabular}


Table 5. Models of the preliminary and final prediction equation

\begin{tabular}{|c|c|c|}
\hline & Preliminary equation & Final equation \\
\hline Equation & $\begin{array}{l}\% \mathrm{FM}=-93.65+0.892\left(\text { height }^{2} / \text { resistance }\right)+ \\
0.064 \text { (resistance) }+2.161(\mathrm{BMI})\end{array}$ & $\begin{array}{l}\% \mathrm{FM}=-74.065+0.671\left(\text { height }^{2} / \text { resistance }\right)+ \\
0.049 \text { (resistance) }+2.08(\mathrm{BMI})\end{array}$ \\
\hline Spearman’s (r) & 0.7 & 0.696 \\
\hline $\begin{array}{l}\% F M(\text { equation) } \\
\text { Mean } \pm \text { SD }\end{array}$ & $24.7 \pm 6.4$ & $24.9 \pm 6.3$ \\
\hline $\begin{array}{l}\% F M \text { (deuterium dilution) } \\
\text { Mean } \pm \text { SD }\end{array}$ & $23.8 \pm 9.0$ & $24.67 \pm 9.2$ \\
\hline
\end{tabular}

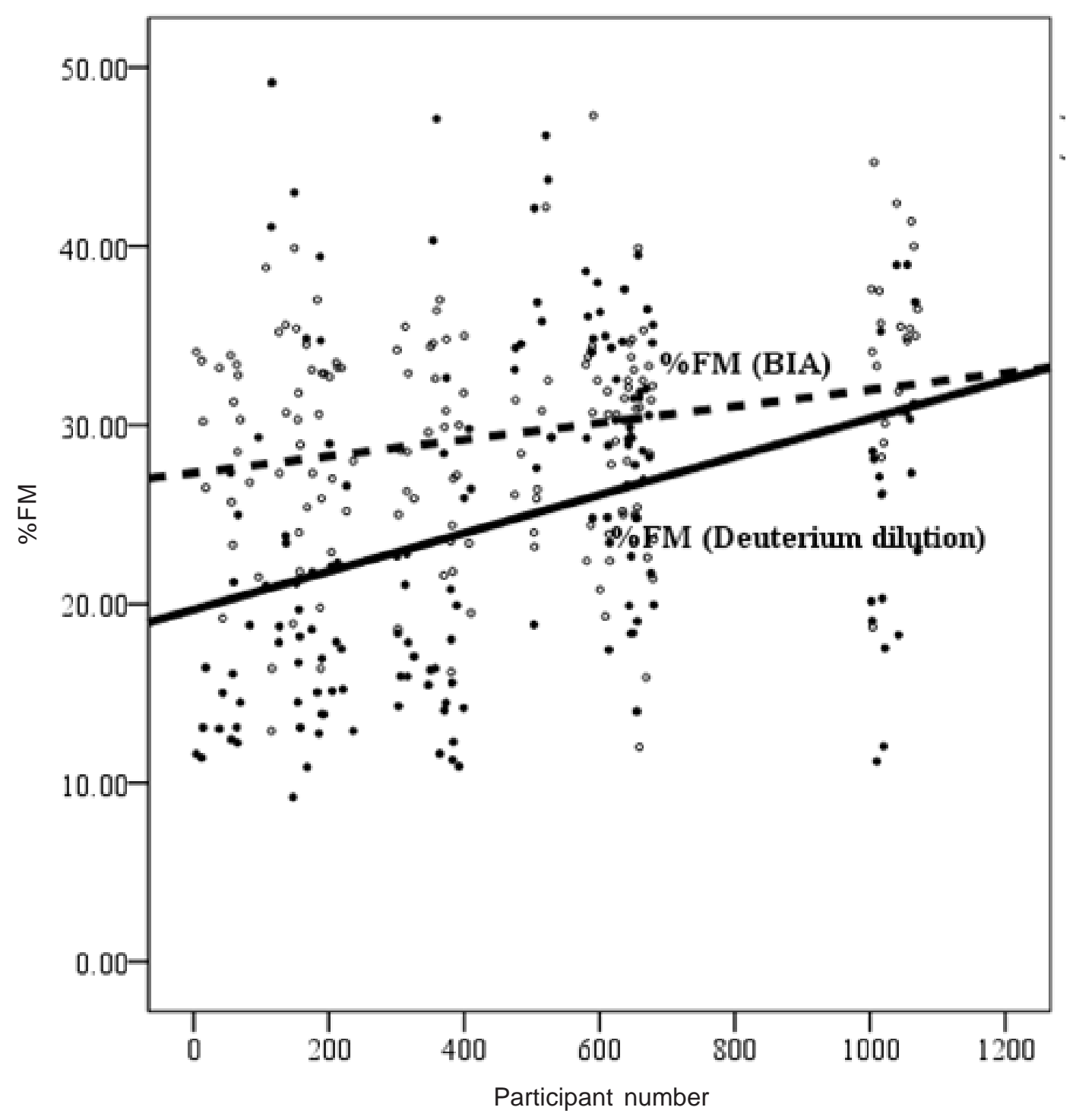

Figure 1. Scatter plots indicating \%FM by BIA and the reference method (deuterium dilution). 


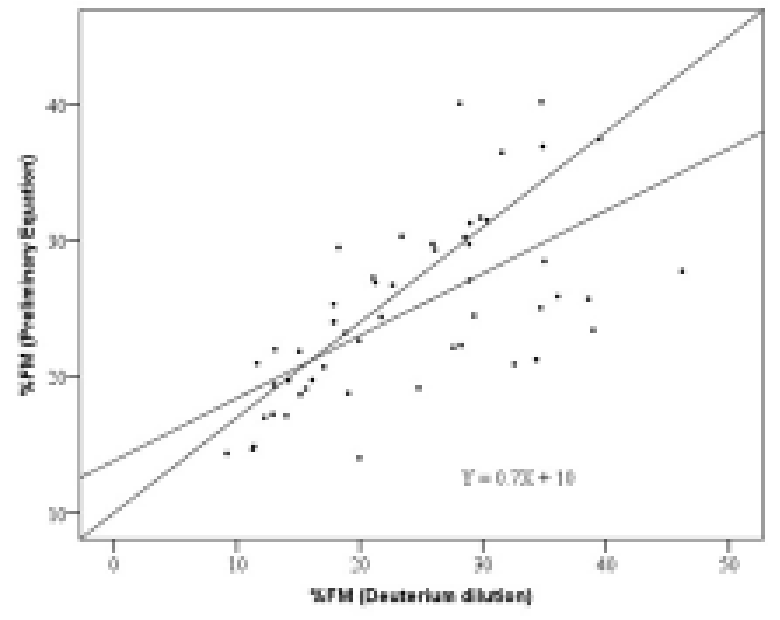

(a) Regression line for \%FM

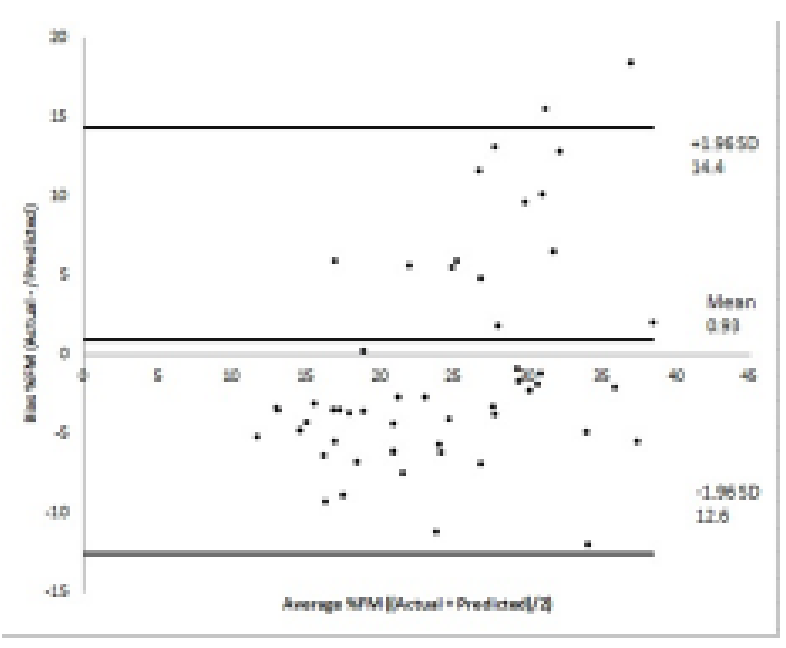

(b) Bland Altman plot difference for \%FM

Figure 2. Association between \%FM (deuterium dilution) and \%FM (preliminary equation).

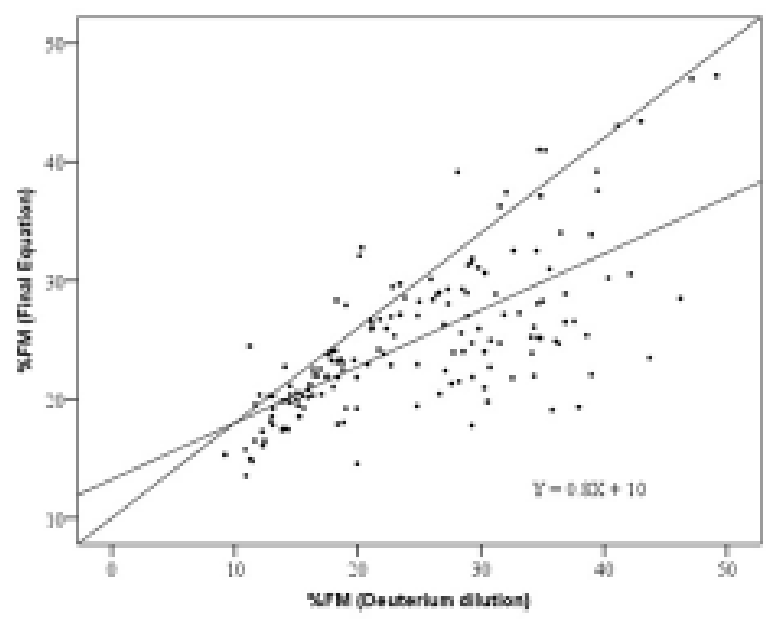

(a) Regression line for \%FM

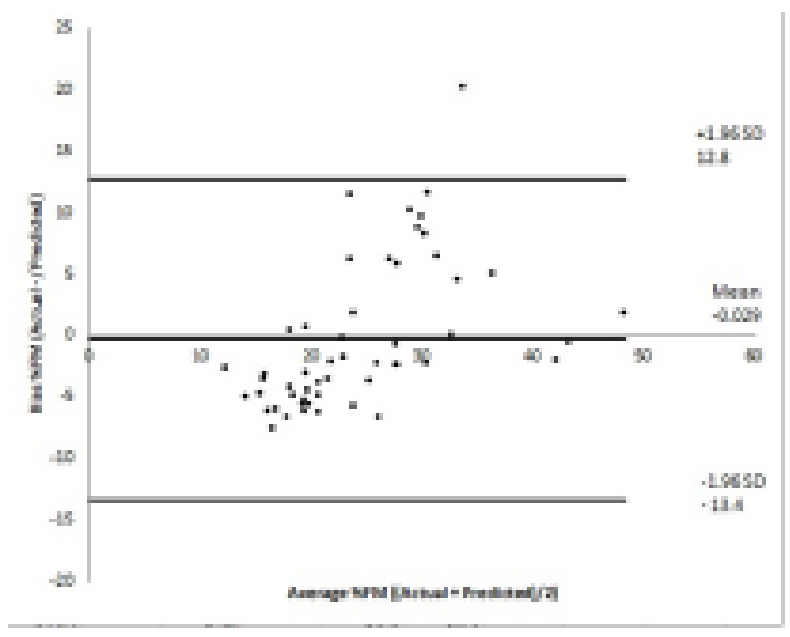

(b) Bland Altman plot difference for \%FM

Figure 3. Association between \%FM (deuterium dilution) and \%FM (final equation).

\section{Derivation of a new BIA equation to predict \%FM}

Age, anthropometric measurements and impedance variables of the validation and cross validation groups were similar (Table 4). The preliminary prediction equation derived for \%FM using the validation group, was derived using \%FM by the reference method as the dependant variable and age, BMI, body weight, resistance and height ${ }^{2} /$ resistance as independent variables. While age and body weight were not significant predictors of \%FM, BMI, resistance and height ${ }^{2} /$ resistance, were the most reliable independent variables $(\mathrm{p}<0.001)$ for prediction of \%FM. The preliminary equation when applied to the cross validation group $(n=53)$ significantly correlated $(r=0.700$, $\mathrm{p}<0.001$ ) with \%FM (deuterium dilution) (Figure 1a). There was no significant difference between \%FM by deuterium dilution and \%FM through the preliminary equation (Table 05). Bland Altman plots for plot difference shown in Figure 1 (b) gave a mean bias of $-0.93 \pm 6.9 \%$.

The final equation was derived following the combination of both the validation and cross validation groups $(\mathrm{n}=160)$, linear regression analysis using \%FM (deuterium dilution) as the dependant variable and BMI, resistance and height ${ }^{2} /$ resistance (identified as the most reliable variables from the preliminary equation) as the independent variables. While there were no significant differences between \%FM obtained by the reference method (deuterium dilution) and the final equation, \%FM (final equation) significantly correlated $(r=0.696, p<0.001)$ with \%FM (deuterium dilution) (Figure 2a) (Table 05). Bland Altman plots used to assess the level of agreement between 
the derived prediction equation and \%FM (deuterium dilution) for plot difference shown in Figure 2(b) gave a mean bias of $-0.29 \pm 6.7 \%$.

\section{Discussion}

To our knowledge, this is the first BIA equation for the prediction of \%FM in post pubertal girls of Sri Lankan origin and would be of use in screening for excess body fat among adolescent girls in Sri Lanka. The new equation is simple and only includes height ${ }^{2} /$ resistance, which can be obtained from the BIA machine and BMI, easily obtained by height and weight measurements as variables. The inclusion of BMI in the equation indicates that it is a valuable component in body fat assessment, though on its own it may be prone to error. Though previous BIA equations too included height ${ }^{2} /$ resistance as a prediction variable (14-16), body weight and age, which are common variables in other prediction equations (10), body weight may have been eliminated due to the inclusion of BMI into our equation and age, due to the narrow age range of our study population.

The results of this study indicate that direct use of \%FM from BIA is inappropriate, and would possibly result in erroneous classification of a majority of adolescent girls as having excess body fat. Direct assessment by the BIA was shown to overestimate \%FM in the population, with underestimation of \%FM of girls who were classified as having excess fat mass by the reference method. Similar to our results, Sun et al (5), reported that BIA tends to overestimate fat mass when subjects are relatively lean (fat mass $<25 \%$ ) and underestimate fat mass when subjects are overweight or obese (\%FM > 33\%).

Due to the lack of BIA equations for the prediction of $\% \mathrm{FM}$ of South Asian adolescent girls, the other equations that we used were those derived on Caucasian or African American children who were younger but of similar weight and height to our population $(15,16)$. The fact that our study population was post pubertal, despite being the same weight and height, may partly account for the poor validity of such equations when applied to our population. The Kushner equation was selected as its wide age range ( 0.22 - 66 years) included our age range of 15 - 19 years (14). However, this too was found to be unsuitable. The equation by Wickramasinghe et al was selected as it included children of Sri Lankan origin, and that by Liu et al (17) was selected as it included children of Asian origin. However, both equations were for the calculation of FFM and was based on the assumption that FM may be calculated by the subtraction of fat free mass from bodyweight. Further, both equations were developed on children $<15$ years of age, while our population was post pubertal adolescents, making these equations unsuitable for our population.
Therefore, we deduce that existing BIA equations for the prediction of \%FM were not suitable for post pubertal adolescents, as they overestimated \%FM, compared to the reference method. This evidence further supports the consensus that population specific equations are essential in assessing fat mass by BIA.

The new BIA equation for the prediction of \%FM of 15 - 19 year old Sri Lankan adolescent girls, significantly correlated with the reference method of deuterium dilution. The Bland Altman plot for comparison of two methods further illustrates accuracy of the new prediction equation. The mean difference between the actual and predicted \%FM (mean bias) was close to zero (mean bias: - 0.29\%) and had only one individual with residuals exceeding the $95 \%$ confidence limits of \%FM. In conclusion, the new BIA equation can be used for the estimation of \%FM of post pubertal adolescent girls in Sri Lanka and is possibly suitable for other adolescent girls of South Asian origin.

\section{Acknowledgments}

The authors thank Thisira Andrahennadhi, Department of Biochemistry and Molecular Biology, Faculty of Medicine, University of Colombo for technical assistance.

\section{References}

1. Misra A,Vikram NK, Arya S, Pandey RM, Dhingra V, Chatterjee A, Dwivedi M, Sharma R, Luthra K, Guleria R, Talwar KK. High prevalence of insulin resistance in postpubertal Asian Indian children is associated with adverse truncal body fat patterning, abdominal adiposity and excess body fat. International Journal of Obesity 2004; 28: 1217 26.

2. de Onis M, Onyango AW, Borghi E, Siyam A, Nishida C, Siekmann J. Development of a WHO growth reference for school-aged children and adolescents. Bulletin of World Health Organisation 2007; 85: 660 - 7

3. Kyle UG, Bosaeus I, De Lorenzo AD, Deurenberg P, Elia $\mathrm{M}$, et al. Bioelectrical impedance analysis - part 1: review of principles and methods. Clinical Nutrition 2004; 23 : 1226 - 43.

4. Williams CA, Bale P. Bias and limits of agreement between hydrodensitometry, bioelectrical impedance and skinfold calipers measures of percentage body fat. European Journal of Applied Physiology and Occupational Physiology 1998; 77(3): $271-7$.

5. Sun G, French CR, Martin GR, Younghusband B, Green RC, Xie Y, Mathews M, Barron JR, Fitzpatrick DG, Gulliver W, Zhang H. Comparison of multifrequency bioelectrical impedance analysis with dual-energy X-ray absorptiometry for assessment of percentage body fat in a large, healthy population. American Journal of Clinical Nutrition 2005; 81: 74 - 8 . 
6. Pimentel GD, Bernhard AB, Frezza MRP, Rinaldi AEM, Burini RC. Bioelectric impedance overestimates the fat mass in overweight and underestimates in Brazilian obese women: a comparison with Segal equation. Nutricion Hospitalaria 2010; 25(5): 741 - 5.

7. Wickramasinghe VP, Lamabadusuriya SP, Cleghorm GJ, Davies PSW. Assessment of body composition in Sri Lankan children: validation of a bioelectrical impedance prediction equation. European Journal of Clinical Nutrition 2008; 62(10): 1170 - 7.

8. Wabitsch M, Braun U, Heinze E, Muche R, Mayer H, Teller W, Fusch C. Body composition in 5 - 18-year old obese children and adolescents before and after weight reduction as assessed by deuterium dilution and bioelectrical impedanceAnalysis. American Journal of Clinical Nutrition 1996; 64: 1-6.

9. Sun SS, Chumlea WC, Heymsfield SB, Lukaski HC, Schoeller D, Friedl K, Kuczmarski RJ, Flegal KM, Johnson CL, Hubbard VS. Development of bioelectrical impedance analysis prediction equations for body composition with the use of a multicomponent model for use in epidemiologic surveys. American Journal of Clinical Nutrition 2003; 77: 331 - 40 .

10. Dioum A, Gartner A, Cissé AS, Delpeuch F, Maire B,Wade S, Schutz Y. Validity of impedance-based equations for the prediction of total body water as measured by deuterium dilution in African women. American Journal of Clinical Nutrition 2005; 81: 597-604.
11. Assessment of body composition and total energy expenditure in humans using stable isotope techniques. IAEA Human Health Series No. 3, Vienna: International Atomic Energy Agency, 2009.

12. Jennings G, Bluck L, Wright A, Elia M. The use of infrared spectrophotometry for measuring body water spaces. Clinical Chemistry 1999; 45(7): 1077-81.

13. de Lanerolle-Dias M, de Silva A, Lanerolle P, Arambepola C, Atukorala S. Body fat assessment in Sri Lankan adolescent girls: development of a simple field tool. Annals of Human Biology 2011; 38(3): 330-6.

14. Kushner RF, Schoeller DA, Fjeld CR, Danford L. Is the impedance index $\left(\mathrm{ht}^{2} / \mathrm{R}\right)$ significant in predicting total body water? American Journal of Clinical Nutrition 1992; 56: 835 - 9.

15. Bray GA, DeLany JP, Harsha DW, Volaufova J, Champagne CC. Prediction of body fat in 12-y-old African American and white children: evaluation of methods. American Journal of Clinical Nutrition 2002; 76: 980-90.

16. Houtkooper LB, Lohmann TG, Going SB, Hall MC. Validity of bioelectrical impedance for body composition assessment in children. Journal of Applied Physiology 1989; 66: 814-21.

17. Liu A, Byrne NM, Ma G, Nasreddine L, Trinidad TP, Kijboonchoo K, Ismail MN, Kagawa M, Poh BK, Hills AP. Validation of bioelectrical impedance analysis for total body water assessment against the deuterium dilution technique in Asian children. European Journal of Clinical Nutrition 2011; 65: $1321-7$. 